Revista de Filología Románica

ISSN: 0212-999X

http://dx.doi.org/10.5209/RFRM.58166

\title{
Maestros frente a docentes
}

Ignacio Bosque ${ }^{1}$

Recibido: 17 de julio de 2017 / Aprobado: 4 de octubre de 2017

Resumen. El autor repasa los años de formación de Alonso Zamora Vicente en la Facultad de Filosofía y Letras de la Universidad Complutense de Madrid con sus maestros, da cuenta de la importancia que tuvo para él la transmisión de las ideas recibidas y explica que la Universidad debe ser centro de docencia e investigación, pero también de formación y crecimiento para los estudiantes. Finalmente, sostiene que la organización de la Universidad actual no facilita el surgimiento de maestros.

Palabras clave: Alonso Zamora Vicente; Facultad de Filosofía y Letras; Universidad Complutense de Madrid.

\section{Masters versus teachers}

\begin{abstract}
Alonso Zamora Vicente's formative years at Complutense University of Madrid were very significant in his career that moment, he not only succeeded in trasmiting and developing the received view of the University, but also in pursuing his conception of this institution as a place to grow up both personally and professionally.
\end{abstract}

Keywords: Alonso Zamora Vicente; Facultad de Filosofía y Letras; Complutense University of Madrid.

Cómo citar: Bosque, I. (2017). Maestros frente a docentes, en Revista de Filología Románica 34. Núm. especial, 159-163.

Imagínense ustedes una Facultad de Letras; una Facultad de Letras como cualquiera de las nuestras, con la salvedad de que en ella imparten docencia a la vez Menéndez Pidal, Américo Castro, Ortega y Gasset, Navarro Tomas, Fernández Montesinos y Pedro Salinas. Imagínense ustedes que se cruzan con cualquiera de ellos por los pasillos, que asisten a sus clases, que estos profesores les corrigen sus exámenes, que pueden ustedes visitarlos en sus despachos cuando les apetece, y que ellos se desviven por atenderles y por ayudarles. Parece un relato de ficción, pero no lo es. Se trata de la Facultad de Letras de la Universidad de Madrid en la que estudió Alonso Zamora Vicente. Imagínense ahora otra, mucho más cercana, en la que don Alonso imparte clase en el mismo departamento en que lo hacen Dámaso Alonso y Rafael Lapesa, y que ustedes son estudiantes que pueden disfrutar de su magisterio, hacerles preguntas, plantearles dudas e inquietudes o pedirles que les dirijan sus trabajos.

$1 \quad$ Universidad Complutense de Madrid y Real Academia Española Email: ibosque@ucm.es 
Don Alonso vivió un tiempo en el que los grandes nombres de nuestra cultura reciente eran personas de carne y hueso que uno se podía encontrar en cualquier lugar. A ello se añade que, como sabemos, don Alonso conoció personalmente -dentro o fuera de España- a Jorge Luis Borges, a Julio Cortázar, a Vicente Alexandre, a Gerardo Diego y a tantas y tantas figuras que a todos nos costaría imaginar como interlocutores en una charla informal. Nos tenemos que conformar con intuir algunos rasgos de su personalidad a través de sus textos y de sus biografías. Pero la Facultad de Letras en la que se formó Alonso Zamora Vicente no destacaba únicamente por su espléndido plantel de profesores. En un texto de 1987 (Zamora Vicente 2010:58) escribía él estas palabras:

Un universitario de aquel tiempo llegaba a la facultad con un número de lecturas muy grande, superior al de un joven de hoy en día. [...] No existía ese invento llamado televisión, y se leía, se leía muchísimo. Madrid estaba lleno de carritos en los que por setenta céntimos, y revolviendo un poco en el montón, podían encontrarse los clásicos: Gracián, Cervantes, Lope de Vega, Calderón, Tirso. Sí, se llegaba a la facultad con una cantidad importante de lecturas, y prácticamente todos habían leído a Cervantes.

Observen que don Alonso no dice que unos pocos estudiantes tuvieran un gran bagaje de lecturas, sino que todos lo tenían. Se dirá probablemente que aquella universidad era casi familiar; que eran muy pocos los que estudiaban, si se comparan aquellos porcentajes con los actuales. No me extrañaría que alguno llegara incluso a rechazar la Universidad de aquellos años por su carácter de institución minoritaria, confundiendo una vez más la excelencia con el elitismo.

Aquella universidad valoraba enormemente algo que casi ha desaparecido de nuestro horizonte educativo actual, algo que don Alonso siempre resaltó en sus escritos: aquella universidad tenía maestros. Don Alonso lo fue, como lo fueron los que iniciaron e impulsaron su espléndida formación académica. Como ustedes saben, don Alonso fue profesor en las universidades de Santiago, Salamanca y Madrid, y dirigió grupos de investigadores en el Instituto de Filología de Buenos Aires y en el Colegio de México, entre otras instituciones. Formó, pues, a un gran número de discípulos, y les transmitió actitudes, saberes y métodos, buena parte de los cuales había recibido a su vez de sus maestros.

Don Alonso creía profundamente en la Universidad, y no solo como centro de docencia y de investigación, sino también como lugar de formación y de crecimiento, a la vez profesional y personal. Creía firmemente en el privilegiado papel que ejerce el maestro como guía, como consejero, como fuente de información y de estímulo. Como es lógico, del alumno se espera esfuerzo, interés y dedicación; del maestro se espera que trace caminos, que desbroce terrenos, que contagie entusiasmos, y también que marque los senderos que juzga equivocados. Se espera de él que sea juez, acicate, fuente de inspiración, de conocimiento y de conducta. Sus profesores fueron todo eso para don Alonso -nos lo ha contado muy bien en sus textos-, y él lo supo ser a su vez para sus alumnos.

En un discurso de $2002^{2}$ refiere don Alonso unas palabras que le transmitió Karl Vossler en una conversación que ambos tuvieron en 1945. Vossler le dijo: "No olvi-

2 Pronunciado con motivo de su investidura como Doctor Honoris Causa por la Universidad de Alicante. 
de esto: No habrá mayor satisfacción para un profesor que aprender algo nuevo de los que antes fueron sus discípulos". En múltiples escritos, charlas, conferencias y discursos hizo referencia don Alonso a esa imagen de la Universidad como cadena infinita de conocimientos e inquietudes. Más aún, a la sensación que percibe el que ha tenido el privilegio de formar parte de esa cadena sin fin la llamaba don Alonso "el gozo de vernos prolongados". Es un sentimiento que quizá solo podrán comprender cabalmente aquellos de ustedes que hayan tenido maestros, o aquellos de ustedes que hayan tenido discípulos. Para don Alonso, esta era una sensación muy viva, muy poderosa, y hoy quiero recordarla ante ustedes porque alguna vez apareció también en las conversaciones que pude tener con él.

Estos días estamos reviviendo numerosas facetas de su vida, de su obra y de su figura. Mis recuerdos de don Alonso coinciden en gran medida con los de quienes nos han transmitido los suyos en estas jornadas. Somos, en efecto, muchos los que pudimos disfrutar en algún momento de su aguda ironía, de su proverbial liberalidad y bonhomía, así como de esa distancia - unas veces benévola y otras socarronaque se percibía en sus comentarios sobre casi todo aquello que le importaba. Alguna vez hablé con él de la Universidad, y percibí - como han hecho otros- la nostalgia que despertaban en él los tiempos a los que me acabo de referir. Nunca le oí un comentario desdeñoso sobre la Universidad española de hoy, de la que se limitaba a decir que es "otra cosa", una forma sabia de dejar el juicio a la perspicacia del buen entendedor.

En una entrevista de 1999 a Madrygal. Revista de Estudios Gallegos, don Alonso confesaba que de niño soñaba con ser maquinista de trenes. No aclaraba allí si el placer que asociaba con la conducción de un tren lo produciría el camino que se va abriendo ante el maquinista, la sensación que percibe el que ve acercarse el paisaje a la vez que se adentra en él, o tal vez la satisfacción de llevar detrás un nutrido grupo de pasajeros que confían - acaso involuntariamente- en la pericia del conductor para llegar a su destino. Nada más lejos de mi ánimo que jugar gratuitamente al psicoanálisis, pero se me ocurre pensar que tal vez el atractivo que veía don Alonso de niño en el hecho de conducir una locomotora resultara de mezclar dos sensaciones: la de ir abriendo caminos y la de transportar por él a quienes deciden libremente embarcarse en el viaje.

Por unas razones o por otras, en los dos o tres últimos años han caído en mis manos innumerables documentos sobre los cambios en la docencia y en la investigación que necesita nuestra Universidad. Muchos de ellos hacen referencia a la necesidad de instaurar nuevas sinergias, redefinir competencias, redimensionar objetivos, fijar destrezas, renovar desarrollos curriculares e implementar nuevas dinámicas del aprendizaje. No seré yo el que cuestione la idoneidad de todas estas actuaciones. Me limito a constatar que hasta hoy no he encontrado un solo texto que resalte -así sea veladamente- la importancia de tener maestros. No sé si ello es así porque no existen, que yo sepa, cursillos de capacitación pedagógica para crearlos. Supongo que la aparente laguna se debe más bien a que hoy se considera que los avances en las nuevas tecnologías, en los materiales didácticos y bibliográficos disponibles y en las renovadas técnicas pedagógicas nos permiten prescindir de esa antigua y venerable figura. Me sitúo, pues, en el reducidísimo grupo de los que pensamos exactamente lo contrario. Formo parte del exiguo reducto de los que aún creemos en la cadena de estímulos, contagios y saberes a la que me acabo de referir. Me inscribo en el bando, absolutamente minoritario, de los que seguimos convenci- 
dos de que ni los nuevos medios pedagógicos ni las nuevas Tecnologías de la Información y la Comunicación (TICs), como ahora se dice, suplen la labor de los maestros, aunque solo sea por el simple hecho de que todos esos recursos ayudan a obtener información, mientras que los maestros enseñan a pensar.

Decía Ortega y Gasset -y lo recordaba don Alonso en uno de sus textos- que en otros países una persona puede convencer de algo a otra con argumentos, mientras que en España es difícil que lo consiga. En España podrá seducirla, encandilarla o engatusarla; podrá incluso negociar con ella y llegar a un acuerdo o un a ten con ten; pero convencer a alguien con argumentos es una tarea casi imposible entre nosotros. Así pues, aquellos de ustedes que tengan capacidad persuasiva, seductora, encandiladora o negociadora tal vez puedan en algún momento hacer llegar a los que deciden sobre estas importantes cuestiones la simple idea de que -además de establecer sinergias, implantar dinámicas y renovar objetivos-, nuestra Universidad necesita maestros; figuras que, como la de don Alonso, supieron esforzarse con abnegación en tiempos de penuria; que recibieron mucho y que dieron mucho; que supieron estimular y abrir caminos; que ayudaron a moldear la capacidad crítica de sus alumnos; que formaron, a lo largo de muchos años, un gran número de profesionales exigentes en la enseñanza y en la investigación de nuestra lengua y nuestra literatura.

Pero me doy perfecta cuenta de que es posible solicitar a los poderes públicos más medios económicos y mejores recursos organizativos, pero no es posible -así, sin más- "pedir maestros". Podríamos, a lo sumo, perseguir un sistema educativo en el que estos pudieran surgir, lo que - desde luego- no parece que pueda conseguirse a golpes de decreto-ley. En cualquier caso, les confesaré, con un punto de tristeza, que, entre la ingente maraña de disposiciones administrativas y de normas curriculares que hoy están a nuestro alcance, he sido incapaz de encontrar un pequeño hueco en el que pudiera tener cabida la sensación que de manera tan exacta describió don Alonso: "el gozo de vernos prolongados".

\section{Referencias bibliográficas}

AA. VV. (1999): "Entrevista a Alonso Zamora Vicente, Catedrático de Filoloxía Románica e Académico da Lingua". Madrygal. Revista de Estudios Gallegos 2:201-206.

Zamora Vicente, Alonso (2002): Discurso pronunciado por el Excmo. Sr. D. Alonso Zamora Vicente con motivo de su investidura como Doctor Honoris Causa por la Universidad de Alicante, 5 de marzo de 2002. Alicante, disponible en https://web.ua.es/es/protocolo/documentos/eventos/honoris/zamora-vicentealonso-2002/discurso-alonso-zamora-vicente.pdf [consulta 12/09/2017].

Zamora Vicente, Alonso (2010): Recuerdos filológicos y literarios, M. Pedrazuela Fuentes (ed.). Cáceres: Universidad de Extremadura. 